\title{
The Effects of Individual Experience on Learning Style: An Investigation on Adolescents
}

\author{
Meishan Zhou ${ }^{1, *}$

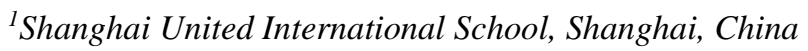 \\ *Corresponding author email: guanghua.ren@gecacademy.cn
}

\begin{abstract}
Much research was done on the role of experience in shaping cognitive abilities, especially learning. However, it is unclear whether if experience also determines our method of learning, which is considered as 'learning style'. Therefore, in this study, an experiment was conducted on 33 adolescents (20 females) to test their extent of visual/auditory/kinesthetic (abbreviated as V/A/K) learning style preference. The relationship between learning style and their level of $\mathrm{V} / \mathrm{A} / \mathrm{K}$ experience collected from questionnaires was analysed. The results showed that there was no significant correlation between the two variables, indicating that despite experience can shape our learning abilities, it does not necessarily influence our learning style. What impacts learning style preference and how can we alter it remains unclear. Further investigation is needed to monitor individuals' long-term changes and explore the neural mechanisms of learning.
\end{abstract}

Keywords: Experience, Learning, VAK learning style, Individual differences

\section{INTRODUCTION}

Experience is unique to all individuals; it is why people are different and have distinct abilities in processing information. It is evidenced that experience heavily influences our behavioral profile, more specifically our cognitive abilities, such as learning [1]. Learning involves perception and comprehension of knowledge, which differ for individuals, making it a unique experience-based process. People prefer different ways of learning, and Barbe (1979) summarised the majority's general types of preference into three categories: visual, auditory, and kinesthetic (abbreviated as $\mathrm{V} / \mathrm{A} / \mathrm{K})$. Visual learners learn most efficiently through visual displays, auditory learners through verbal speech, and kinesthetic through active movement and touch. Knowing one's correct preference of learning can make the learning process more efficient and effective, improving the quality of education. Results of studies in this field are highly applicable; individuals establish unique ways of knowledge perception and processing, if we can determine the factors influencing such development, we might be able to predict the growth patterns of individuals and adjust education accordingly.

Previous research focused on inborn factors and V/A/K learning style preference, such as gender [2] [3]. However, there's little investigation into postnatal factors. Since experience plays a significant role in shaping our cognitive ability -- learning, it is worth questioning whether if experience, as an environment factor, influences our learning preference as well. There's evidence of a high level of experience in correlation with particular sensory performance, especially in V/A/K areas. Artists reported that their experience from career aids visual memory, attention to detail, and identification of shapes when it comes to other visual activities [4]. Musicians demonstrated faster neural timing and better response to diotically given auditory stimuli [5]. Marksmen showed higher efficiency in motor tasks than novice shooters due to their faster cortical activation from long-term practice [6]. In all three cases, professionals outperform non-professionals; this proves long-term experience to aid our sensory performances in the area of practice.

It is deducted that during the process of learning, people prioritise their most capable and skilled sensory system to perceive information. Hence, to prove this presumption, this study will look into the relationship between a high level of V/A/K experience, and the extent of V/A/K learning style preference. The investigation was launched on 13-18 years old adolescents. This age group was chosen purposefully, as they provide an ideal sample for investigation on experience. Many thorough investigations examined adolescence as a sensitive period 
for brain development and compared cognitive training results with adulthood [7, 8]. Evidence shows that due to neuroplasticity the adolescent brain is very susceptible to changes and long-term stimuli, thus, experience. Adolescent brains are also not fully matured, and their learning style preference has not yet fixed. That leaves a region of flexibility for experience to fully have an effect, aiding the purpose of this study. Additionally, previous studies, including the most recent ones, focused mostly on early or late adulthood [9]. The group of adolescents lack adequate investigation, and it is unknown whether if conclusions on adults can equally apply to younger age groups. This creates a gap in the exploration of learning styles, which this study aims to fill.

It is hypothesised that a high level of experience in $\mathrm{V} / \mathrm{A} / \mathrm{K}$ areas correspondingly leads to strong $\mathrm{V} / \mathrm{A} / \mathrm{K}$ learning style preference. To test the assumption's validity, 33 Participants were chosen as sample. Participants' past experiences on $\mathrm{V} / \mathrm{A} / \mathrm{K}$ education were collected using a questionnaire. An experiment requiring learning with $\mathrm{V} / \mathrm{A} / \mathrm{K}$ method was also conducted to assess their performance in each area, and hence their $\mathrm{V} / \mathrm{A} / \mathrm{K}$ preference in learning. The correction between level of experience and learning style preference was later analysed in order to verify the research hypothesis.

\section{METHODS}

\subsection{Participants}

The study sample is composed of 33 Chinese highschool students, 20 are females and 13 are males, all between the ages of 13-38. They were recruited from Shanghai United International School and Beijing 21st Century International School, through social media advertisements. All participants have fully capable cognitive abilities and have received compulsory education. For experiment purpose, study samples were selected across the school from art classes, music bands, sports teams, and drama groups. Before the experiment, all participants were informed about the intention of this study and has read the consent form. The names of the participants are anonymised to numerical codes for privacy protection. Gifts between the price of $¥ 10-20$ were given to each participant as remuneration.

\subsection{Materials and design}

The independent variable of this study is the individual experience of participants. This is examined through three aspects -- level of visual experience, auditory experience, and kinesthetic experience. The dependent variable is participants' learning style preference. Information for independent variable is collected using a self-compiled questionnaire, which records participants' past experiences and level of professionalism in $\mathrm{V} / \mathrm{A} / \mathrm{K}$ areas. The latter value is assessed as the level of $\mathrm{V} / \mathrm{A} / \mathrm{K}$ experience used in later analysis.

The dependent variable, V/A/K leaning style preference, is measured through a self-designed experiment made by PsychoPy. Participants are required to complete three tasks; each task teaches three recipes, hence nine recipes in total. For each recipe, there is the teaching trial and the quiz trial. The teaching trial gives information for participants to learn, and the quiz trial tests for the knowledge participants received. The three tasks teach participants using different stimuli, which is visual, auditory, and kinesthetic. The visual teaching trial displays static images to show the cooking procedure; after an image is shown, it pops of and the next one appears consecutively. The auditory teaching trial plays a pre-recorded audio file, including a female voice stating the recipe procedures without tonal change; while the file is playing, the screen does not display any words or images related to the recipe. The kinesthetic teaching trial presents a computer game for participants, where they need to click on the food or the utensil to continue the next step. The quiz trial asks for information previously given in the teaching trial and is used to assess the participant's learning results. Accuracy rate of visual learning, auditory learning and kinesthetic learning is compared; the higher the accuracy rate, the stronger the preference the participant has towards that learning style. The order of $\mathrm{V} / \mathrm{A} / \mathrm{K}$ learning session is completely random for all participants, they may get the order $\mathrm{V}-\mathrm{A}$ $\mathrm{K}, \mathrm{V}-\mathrm{K}-\mathrm{A}, \mathrm{A}-\mathrm{V}-\mathrm{K}, \mathrm{A}-\mathrm{K}-\mathrm{V}, \mathrm{K}-\mathrm{A}-\mathrm{V}$ and $\mathrm{K}-\mathrm{V}-\mathrm{A}$. This is to prevent systematic errors; if the order is fixed, participants may consistently perform the latter session better due to familiarity. The recipes taught are designed using randomly generated food, hence are non-existing. This is to ensure that all information is equally new to participants, thus, they must use the process of learning. All the participants have Mandarin as their native language; therefore, the entire experiment was conducted in Mandarin. 


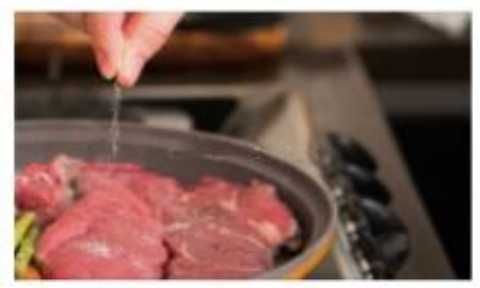

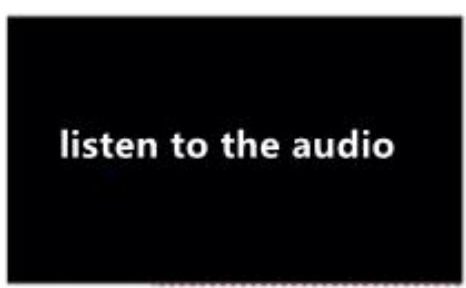

C

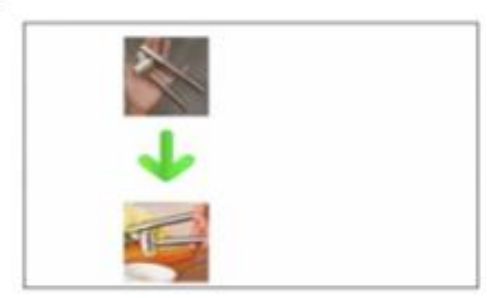

Figure 1 Example of V/A/K learning trials. A shows one step of visual teaching, with static image and instruction in the center; B shows auditory teaching, with audio file playing and the words 'please listen to the audio clip' in the center; $\mathrm{C}$ shows one step of kinesthetic learning, with an arrow instructing the participant to click and continue the next step.

\subsection{Procedure}

Participants are first given with a questionnaire to complete. Before the first question, they are instructed to answer with honesty. The first two questions ask about the education in $\mathrm{V} / \mathrm{A} / \mathrm{K}$ areas that participants have received in the past, also the time length of this education experience. After the two guiding questions, participants are required to rate themselves on a scale of 1-100 on how professional they think they are in this area (compared to others in their age group).

After the questionnaire is completed, participants enter the second session assessing learning style preference. Before starting, detailed instructions are provided to prevent any confusions. Participants then first receive V/A/K stimuli on some recipe procedures. All three visual and auditory stimuli last for about 32 seconds in total, and each trial shows 8 steps. The time for kinesthetic trial depends on how fast the participants click; the three stimuli also have 8 steps. The learning trial and quiz trial alternates; immediately when one recipe is taught, a quiz is given to test the previous information. When the answer of the quiz is typed in, teaching trial for the next recipe starts. This order is consistent for all nine recipes.

\subsection{Data analysis}

Accuracy rate of V/A/K learning quiz was calculated for all participants. Afterwards, statistical analysis was carried out using IBM SPSS Statistics. The correlation between the level of $\mathrm{V}$-experience and $\mathrm{V} / \mathrm{A} / \mathrm{K}$ accuracy rate is calculated, followed by the level of A-experience and V/A/K accuracy rate, and the level of K-experience and V/A/K accuracy rate. Pearson correlation analysis was performed, the a priori probability level of $p \leqslant .05$ (2-tailed) was selected.

\section{RESULTS}

The average level of $\mathrm{V} / \mathrm{A} / \mathrm{K}$ experience is demonstrated in figure 2 and the average accuracy rate of
$\mathrm{V} / \mathrm{A} / \mathrm{K}$ learning is demonstrated in figure 3. From the two figures we cannot see a clear relationship. The overall auditory experience is the highest (47.15), but the auditory accuracy rate is the lowest amongst all (.73). Level of visual experience is the lowest (29.45), yet the visual accuracy rate is the same as kinesthetic accuracy rate $(.80)$.

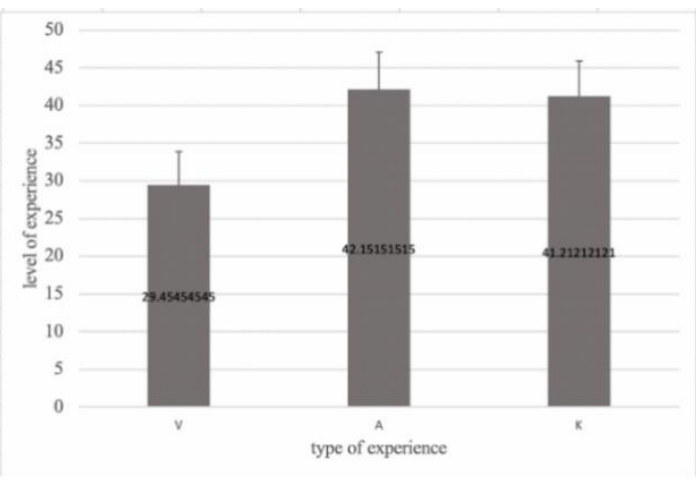

Figure 1 Average level of V/A/K experience for all participants

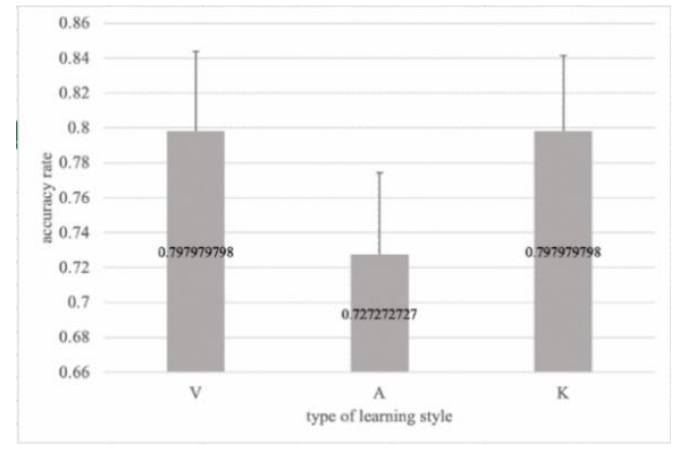

Figure 2 Average accuracy rate of quiz from V/A/K learning for all participants 
Table 1. The correlation between level of V/A/K experience and V/A/K learning style preference

\begin{tabular}{lcccccc}
\hline & \multicolumn{3}{l}{ Type of experience } \\
\cline { 2 - 7 } & \multicolumn{2}{l}{ Visual } & \multicolumn{3}{c}{ Auditory } & \multicolumn{2}{l}{ Kinesthetic } \\
\cline { 2 - 7 } Learning style & $r$ & $p$ & $r$ & $p$ & $r$ & $p$ \\
\hline Visual & .261 & .143 & .219 & .222 & -.103 & .568 \\
Auditory & .274 & .123 & .071 & .696 & .103 & .567 \\
Kinesthetic & .174 & .332 & .065 & .721 & -.342. & .051 \\
\hline
\end{tabular}

According to the analysis, there is no significant association between a high level of visual or auditory experience and high visual or auditory learning style preference ( $p=.143$ for visual, $p=.696$ for auditory). Level of kinesthetic experience is in weak correlation with strong kinesthetic learning style preference $(p=$ $.051)$, but the correlation in negative $(r=-.341)$. Hence the relationship between independent variables and dependent variables is not proven.

\section{DISCUSSION}

This study looked into the relationship between the level of $\mathrm{V} / \mathrm{A} / \mathrm{K}$ experience and $\mathrm{V} / \mathrm{A} / \mathrm{K}$ learning style preference. It was hypothesised that a higher level of $\mathrm{V} / \mathrm{A} / \mathrm{K}$ experience will correspondingly increase V/A/K learning style preference. However, the result demonstrated that level of visual and auditory experience is unrelated to any kind of learning style preference; meanwhile high level of kinesthetic experience is in weak but negative correlation with kinesthetic learning style preference, opposite to the hypothesis.

This result is inconsistent with earlier findings. According to previous research, artists outperform nonartists in visual perception tasks and exhibit great perceptual advantage in analysing visual stimuli [10]. Also, musicians have an outstandingly higher response to auditory cues (such as music) than non-musicians, and their cognitive function (such as task of language comprehension) is more affected by the presence of music [11]. Additionally, elite karate athletes have higher accuracy rate and lower reaction time for a computer task that requires response to motor cues, compared to nonathletes [12].

Apart from behavioral results, previous research on neuroplasticity demonstrates strong effects of experience on post-natal brain development [13]. A study comparing the visual perception of artists and non-artists shows that artists have the temporooccipital region and frontal cortical region to be more intensely connected [14], indicating that higher-level cognitive skills are linked more strongly with visual stimuli. Comparison on musicians and non-musicians in another study has similar outcomes; musicians with higher-level professionalism possess a larger grey matter volume in Heschl's gyri, where the primary auditory cortex locates [15], hence the auditory cortex is more active for musicians when processing information. Furthermore, long-term practice in sport reduces activation difficulty of the right dorsal premotor cortex in the post-training group [16], indicating an easier use of the motor system when processing information. This study, however, is inconsistent with the majority of previous evidence.

The sensitive period of brain development provides a possible explanation for the outcomes. Despite that some literature proves adolescence to be a second sensitive period for cortical development [17], the more accepted time range is prematurity [18]. Although the V/A/K experience of our participants is long-term (some started at the age of 3 and extends over 13 years), the experience is not concentrated in the first sensitive period, and thus the effects of activity-dependent plasticity are less significant. Additionally, previous studies defined art experience, music experience, and sports experience as receiving extensive professional training; artists were classified as those possessing art degrees, musicians as those practicing music for more than 1 hour a day, and sports trainers as those with 77 hours of single sport practice [14-16]. Participants of this study are all amateurs who might not have enough experience to create a biological change. The lack of professional and routine practice makes the effects of experiences less powerful. This difference in extent of experience could also explain the incongruency.

Despite the results' inconsistencies, this study has innovations compared to prior research. A computer program was used to measure $\mathrm{V} / \mathrm{A} / \mathrm{K}$ learning style preference. Previous research mostly used selfassessment questionnaires that ask for participants to selfevaluate, based on their daily habits, regarding their 
learning preference. Not only does this rely on participants' honesty, but it also leads to erroneousness during the process of self-evaluation. By using the computer program, the performances of participants are directly measured, which reflects the learning outcome straightforwardly, preventing any interference resulting in random errors.

However, there are certain limitations that must not be neglected, which inevitably impacted the accuracy of the results. Most previous studies on experience and cortical development use longitudinal studies to trace the changes [19]. This study can be improved by tracking the participants' performance across time, to compare and verify if increased $\mathrm{V} / \mathrm{A} / \mathrm{K}$ experience can enhance $\mathrm{V} / \mathrm{A} / \mathrm{K}$ preference. Moreover, the gender of participants is neglected as a control variable. Gender difference is evidenced by the asymmetrical grey and white matter in the frontal, temporal, occipital lobe, also Heschl's gyri [20]. These regions correspond to the previously discussed visual and auditory input areas. Therefore, the participant range should be restricted to one single gender. On top of that, participants only learned 3 pieces of information for each learning method $(\mathrm{V} / \mathrm{A} / \mathrm{K})$, and the quiz they received on determining $\mathrm{V} / \mathrm{A} / \mathrm{K}$ preference only includes 3 questions for each style. The small number of questions makes it challenging to distinguish in detail the different performances of participants. Some participants have the same accuracy rate yet contrast greatly in reaction time, demonstrating a further distinction between their $\mathrm{V} / \mathrm{A} / \mathrm{K}$ preference. The variation in preference between participants with the same V/A/K learning accuracy rate was not considered during the experiment, creating a source of inaccuracy in later correlation analysis. Finally, the experiences of participants are neither fully composed of professional trainings nor certified (for example by a degree). This means their experiences might be too shallow to have an extensive impact. Future studies can find participants with professional qualifications and compare them with non-professionals, such as graduates with art degree and people completely new to visual art. This contrast shall emphasise the difference in individual experiences and increase the validity of results.

\section{CONCLUSION}

This study looked into the relationship between level of $\mathrm{V} / \mathrm{A} / \mathrm{K}$ experience and $\mathrm{V} / \mathrm{A} / \mathrm{K}$ learning style preference. The hypothesis was that high level of $\mathrm{V} / \mathrm{A} / \mathrm{K}$ experience would correspondingly lead to strong V/A/K preference. Overall, this study challenges some previous views. The results suggest no significant correlation between the variables; extent of visual or auditory learning style preference is not dependent on level of visual or auditory experience; high kinesthetic experience is negatively correlated with strong kinesthetic learning style preference, which is also the opposite of the prediction. This study has significance in improving our understanding of learning. Our ability to learn is influenced by experience as previous studies suggest, however, our method to learn doesn't seem to be affected, it may have much more complicated factors beyond what is currently understood. Possible explanations include the undefined concept of sensitive period, and the lack of professionalism in the participants' experiences. Both of which reduced the impact of experience in shaping cognitive skills. Some limitations intervened the result validity; the long-term changes in learning style preference are not traced, the number of learning trials is too few to fully distinguish participants' preferences, and the participants' experiences are not strong enough to have a visible impact on cognitive functions. The topic of learning style needs to be explored further, to complete our understanding on individual learning and to improve the approaches to education. Further studies are still needed to determine what shapes our learning style; longitudinal studies can be employed to trace the gradual change in learning style preference as factors are manipulated in long-term. Also, later research involving level of experience could compare professionals and nonprofessionals to amplify the difference and ensure a more targeted comparison.

\section{REFERENCES}

[1] Kowal, M., Toth, A. J., Exton, C., \& Campbell, M. J. (2018). Different cognitive abilities displayed by action video gamers and non-gamers. Computers in Human Behavior, 88, 255-262. https://doi.org/10.1016/j.chb.2018.07.010

[2] Gholami, S., \& Bagheri, M. S. (2013). Relationship between VAK Learning Styles and Problem Solving Styles regarding Gender and Students' Fields of Study. Journal of Language Teaching and Research, 4(4). https://doi.org/10.4304/jltr.4.4.700706

[3] V, P., \& S, W. (2015). GENDE R DIFFERENCES IN LEARNING STYLES AMONG THE FIRST YEAR MEDICAL STUDENTS. Journal of Evolution of Medical and Dental Sciences, 4(89), 15459-15462.

https://doi.org/10.14260/jemds/2015/2209

[4] Schlewitt-Haynes, L. D., Earthman, M. S., \& Burns, B. (2002). Seeing the World Differently: An Analysis of Descriptions of Visual Experiences Provided by Visual Artists and Nonartists. Creativity Research Journal, 14(3-4), 361-372. https://doi.org/10.1207/s15326934crj1434_7

[5] Parbery-Clark, A., Strait, D. L., Hittner, E., \& Kraus, N. (2013). Musical Training Enhances Neural Processing of Binaural Sounds. Journal of 
Neuroscience, 33(42),

$16741-16747$.

https://doi.org/10.1523/jneurosci.5700-12.2013

[6] Haufler, A. J., Spalding, T. W., Santa Maria, D. L., \& Hatfield, B. D. (2000). Neuro-cognitive activity during a self-paced visuospatial task: comparative EEG profiles in marksmen and novice shooters. Biological Psychology, 53(2-3), 131-160. https://doi.org/10.1016/s0301-0511(00)00047-8

[7] Fuhrmann, D., Knoll, L. J., \& Blakemore, S.-J. (2015). Adolescence as a Sensitive Period of Brain Development. Trends in Cognitive Sciences, 19(10), 558-566. https://doi.org/10.1016/j.tics.2015.07.008

[8] Knoll, L. J., Fuhrmann, D., Sakhardande, A. L., Stamp, F., Speekenbrink, M., \& Blakemore, S.-J. (2016). A Window of Opportunity for Cognitive Training in Adolescence. Psychological Science, 27(12), 1620-1631. https://doi.org/10.1177/0956797616671327

[9] Gamboa Mora, M. C., Vera-Monroy, S. P., MejíaCamacho, A., \& Guerrero Rueda, W. J. (2021). Perception channels and cognitive styles: opponents, followers or learning allies? Heliyon, 7(2), e06242. https://doi.org/10.1016/j.heliyon.2021.e06242

[10] Kozbelt, A. (2001). Artists as experts in visual cognition. Visual Cognition, 8(6), 705-723. https://doi.org/10.1080/13506280042000090

[11] Patston, L. L. M., \& Tippett, L. J. (2011). The Effect of Background Music on Cognitive Performance in Musicians and Nonmusicians. Music Perception: An Interdisciplinary Journal,29(2), 173-183. https://doi.org/10.1525/mp.2011.29.2.173

[12] Del Percio, C., Rossini, P. M., Marzano, N., Iacoboni, M., Infarinato, F., Aschieri, P., Lino, A., Fiore, A., Toran, G., Babiloni, C., \& Eusebi, F. (2008). Is there a "neural efficiency" in athletes? A high-resolution EEG study. NeuroImage,42(4), 1544-1553. https://doi.org/10.1016/j.neuroimage.2008.05.061

[13] Fox, S. E., Levitt, P., \& Nelson III, C. A. (2010). How the Timing and Quality of Early Experiences Influence the Development of Brain Architecture. Child Development, 81(1), 28-40. https://doi.org/10.1111/j.1467-8624.2009.01380.x

[14] Bhattacharya, J., \& Petsche, H. (2005). Drawing on mind's canvas: Differences in cortical integration patterns between artists and non-artists. Human Brain Mapping, 26(1), 1-14.

[15] Gaser, C., \& Schlaug, G. (2003). Brain Structures Differ between Musicians and Non-Musicians. The Journal of Neuroscience,23(27), 9240-9245. https://doi.org/10.1523/jneurosci.23-27-09240.2003
[16] Bezzola, L., Mérillat, S., \& Jäncke, L. (2012). The effect of leisure activity golf practice on motor imagery: an fMRI study in middle adulthood. Frontiers in Human Neuroscience, 6. https://doi.org/10.3389/fnhum.2012.00067

[17] Crews, F., He, J., \& Hodge, C. (2007). Adolescent cortical development: A critical period of vulnerability for addiction. Pharmacology Biochemistry and Behavior, 86(2), 189-199. https://doi.org/10.1016/j.pbb.2006.12.001

[18] Als, H., Duffy, F. H., McAnulty, G. B., Rivkin, M. J., Vajapeyam, S., Mulkern, R. V., Warfield, S. K., Huppi, P. S., Butler, S. C., Conneman, N., Fischer, C., \& Eichenwald, E. C. (2004). Early Experience Alters Brain Function and Structure. PEDIATRICS, 113(4), 846-857. https://doi.org/10.1542/peds.113.4.846

[19] Habibi, A., Damasio, A., Ilari, B., Veiga, R., Joshi, A. A., Leahy, R. M., Haldar, J. P., Varadarajan, D., Bhushan, C., \& Damasio, H. (2017). Childhood Music Training Induces Change in Micro and Macroscopic Brain Structure: Results from a Longitudinal Study. Cerebral Cortex, 28(12), 4336-4347. https://doi.org/10.1093/cercor/bhx286

[20] Good, C. D., Johnsrude, I., Ashburner, J., Henson, R. N. A., Friston, K. J., \& Frackowiak, R. S. J. (2001). Cerebral Asymmetry and the Effects of Sex and Handedness on Brain Structure: A Voxel-Based Morphometric Analysis of 465 Normal Adult Human Brains. NeuroImage, 14(3), 685-700. https://doi.org/10.1006/nimg.2001.0857 